\title{
PENGARUH KEADILAN PROSEDURAL TERHADAP KINERJA KARYAWAN DENGAN TINGKAT KEPUASAN KARYAWAN SEBAGAI VARIABEL INTERVENING
}

\author{
Rosita Kharisma Widiastuti \\ Prodi Akuntansi Universitas Negeri Yogyakarta \\ rositakharisma@gmail.com \\ Mimin Nur Aisyah \\ Staf Pengajar Jurusan Pendidikan Akuntansi Universitas Negeri Yogyakarta
}

\begin{abstract}
Abstrak: Pengaruh Keadilan Prosedural terhadap Kinerja Karyawan dengan Tingkat Kepuasan Karyawan sebagai Variabel Intervening. Penelitian ini bertujuan untuk mengetahui: (1) pengaruh langsung keadilan prosedural terhadap kinerja karyawan, (2) pengaruh langsung keadilan prosedural terhadap kepuasan karyawan, (3) pengaruh tidak langsung keadilan prosedural terhadap kinerja karyawan melalui kepuasan karyawan. Penelitian ini adalah penelitian populatif. Penelitian ini menggunakan kuesioner dalam pengumpulan datanya. Teknik uji terpakai menggunakan uji validitas, dan uji reliabilitas. Pengujian hipotesis pertama dan kedua menggunakan uji regresi linear sederhana. Pengujian hipotesis ketiga menggunakan path analysis. Hasil penelitian menunjukkan bahwa (1) keadilan prosedural berpengaruh positif terhadap kinerja karyawan yang ditunjukkan dengan X1 15,119, R Square sebesar 0,391, t hitung 5,999 > t tabel 1,672, (2) keadilan prosedural berpengaruh positif terhadap kepuasan karyawan yang ditunjukkan dengan koefisien X2 sebesar 38,838, R Square sebesar 0,308, t hitung 4,995 > 1,672, (3) keadilan prosedural berpengaruh positif terhadap kinerja karyawan melalui kepuasan karyawan yang ditunjukkan dengan adanya pengaruh mediasi t hitung 2,248 > t tabel 1,672, dan koefisien mediasi 0,0849.
\end{abstract}

Kata Kunci: Keadilan prosedural, Kinerja karyawan, Kepuasan karyawan.

Abstract: The Effect of Procedural Justice on Employee's performance with Employees' satisfaction as Intervening Variable. This research is conducted to examine: (1) the direct effect of procedural justice on the employees' performance; (2) the direct effect of procedural justice on employees' satisfaction; and (3) the indirect effect of procedural justice on employees' performance through employees' satisfaction.

This research is a populative research. This research uses questionnaire in gathering the data. Then, the examination techniques used is the validity test and the reliability test. The examination of first and the second hypothesis uses simple linear regression. The third hypothesis examination uses path analysis to recognize the existing mediation effect. The results of the research showed that (1) procedural justice positively influence employees' performance, it showed by the equation X1 15,119, $R$ Square 0,391, $t$ count 5,995 > t table 1,672, (2) procedural justice positively influence employees' satisfaction, it showed by the equation X2 38,838, $R$ Square 0,308, t count 4,995 > t table 1672, (3) procedural justice positively influence employees' performance through employees' satisfaction, it showed by the mediation effect t count 2,248 > t table 1672, and coefficient mediation 0,0849.

Keywords: Procedural justice, Employees' performance, Employees' satisfaction. 


\section{JURNAL NOMINAL / VOLUME V NOMOR 1 / TAHUN 2016}

\section{PENDAHULUAN}

Sebuah organisasi adalah suatu kesatuan yang di dalamnya terdapat berbagai individu yang memiliki latar belakang yang berbedabeda dan saling bekerjasama untuk mencapai tujuan organisasi. Tercapai atau tidaknya suatu tujuan organisasi sangat dipengaruhi oleh kinerja sumber daya manusia yang ada di dalam organisasi.

Kinerja adalah hasil kerja secara kualitas dan kuantitas yang dicapai oleh seseorang dalam melaksanakan tugas atau pekerjaanya yaitu sesuai dengan tanggung jawab yang telah diberikan kepadanya dan merupakan hasil kerja yang telah dicapai oleh seseorang dengan standar yang telah ditentukan, dengan standar tersebut diharapkan kinerja seseorang dalam sebuah organisasi mampu menghasilkan mutu pekerjaan yang baik serta jumlah pekerjaan yang sesuai dengan standar (Siti Hidayah dan Haryani, 2013).

Keberhasilan suatu perusahaan atau instansi sangat ditentukan oleh salah satunya adalah kinerja dari para karyawannya dalam berbagai bidang. Peran karyawan dalam setiap usaha merupakan faktor yang penting. Oleh karena itu, perusahaan atau instansi harus mampu mengolah sumber daya manusia yaitu karyawan sedemikian rupa sehingga terjadi keseimbangan bagi seluruh karyawan yang ada dalam sebuah perusahaan atau instansi. Keseimbangan yang diciptakan berupa keadilan prosedural. Keadilan prosedural adalah keadilan organisasi yang berhubungan dengan prosedur pengambilan keputusan oleh organisasi yang ditunjukkan kepada karyawannya. Perlakuan adil secara prosedur telah didemonstrasikan dapat meningkatkan kinerja dan kepuasan kerja (Rakhmawati Hijiyanti, 2013). Dalam hal ini, keadilan dikatakan ada apabila karyawan merasa imbalan yang mereka terima sama dengan apa yang karyawan lain terima dengan kinerja dan pekerjaan yang sama. Ketidakadilan terjadi apabila imbalan yang diberikan perusahaan tidak sesuai dengan apa yang karyawan lakukan, dan apa yang karyawan lakukan tidak mendapat hasil sepadan dengan apa yang karyawan lain lakukan dengan tugas dan pekerjaan yang sama yang telah perusahaan berikan. Keadilan bukan berarti sama rata, tetapi sesuai antara pengorbanan dengan penghasilan. Semakin tinggi pengorbanan yang telah dilakukan semakin tinggi juga penghasilan yang diharapkan oleh karyawan.

Equity teory (teori keadilan) menjelaskan bahwa keadilan distributif dan prosedural menunjuk pada persepsi karyawan mengenai kewajaran dan keseimbangan antara masukan yang mereka berikan dalam bentuk pendidikan, latihan, pengalaman, dengan penghargaan yang mereka terima (Hani Handoko, 2003: 267). Dengan demikian, karyawan akan cenderung meminta balas jasa yang sesuai dengan apa yang mereka kerjakan. 


\section{JURNAL NOMINAL / VOLUME V NOMOR 1 / TAHUN 2016}

Terpenuhinya keadilan yang diciptakan perusahaan ataupun instansi secara tidak langsung akan berpengaruh terhadap kepuasan karyawan atas pekerjaan yang mereka lakukan. Kepuasan kerja karyawan, tercermin pada sikap positif yang karyawan berikan terhadap pekerjaannya dengan melaksanakan tanggung jawab secara baik. Kepuasan dalam diri masing-masing karyawan dapat ditumbuhkan oleh perusahaan ataupun instansi dengan cara menerapkan keadilan prosedural sebaik mungkin.

Kepuasan karyawan terhadap perusahaan ataupun instansi diharapkan dapat meningkatkan kinerja dari karyawan dalam mencapai tujuan perusahaan atau instansi tempat mereka bekerja. Kepuasan karyawan terhadap perusahaan ataupun instansi diharapkan dapat meningkatkan kinerja dari karyawan dalam mencapai tujuan perusahaan atau instansi tempat mereka bekerja.

Menyadari akan pentingnya keadilan prosedural terhadap kinerja karyawan serta kemungkinan tingkat kepuasan karyawan sebagai faktor mediasi di dalamnya, maka penulis tertarik untuk melakukan penelitian dengan judul "Pengaruh Keadilan Prosedural terhadap Kinerja Karyawan dengan Tingkat Kepuasan Karyawan sebagai Variabel Intervening (Studi pada Pegawai Bagian Keuangan Universitas Negeri Yogyakarta".

\section{METODE PENELITIAN}

\section{Populasi dan Sampel Penelitian}

Populasi dalam penelitian ini adalah seluruh pegawai pada bagian keuangan di Universitas Negeri Yogyakarta, baik karyawan tetap maupun kontrak (outsorcing). Populasi dalam penelitian ini berjumlah 74 pegawai.

Populasi diambil seluruhnya untuk dijadikan responden karena relatif kecilnya jumlah pegawai yakni sejumlah 74 pegawai, hal ini bertujuan untuk mengantisipasi tingkat pengembalian kuesioner (response rate) yang rendah.

\section{Data, Intrumen, dan Teknik Pengumpulan}

Penelitian ini menggunakan data primer. Menurut Sugiyono (2014: 137), data primer adalah data yang didapatkan secara langsung dari sumber data. Data primer tersebut didapatkan peneliti dari hasil kuesioner yang dibagikan kepada karyawan bagian keuangan di Universitas Negeri Yogyakarta.

Instrumen yang digunakan dalam penelitian ini adalah kuesioner atau angket yang butir-butir pertanyaannya diadopsi dan dimodifikasi dari penelitian Rakhmawati Hajiyanti Muji Rahayu (2013) dan Elis Sholihah (2014). Kuesioner atau daftar pertanyaan ini berisi tentang variabel terikat ( Kinerja Karyawan), variabel bebas (Keadilan Prosedural), dan variabel mediasi (Kepuasan Karyawan) yang menggunakan skala sikap model likert 4 poin. 


\section{JURNAL NOMINAL / VOLUME V NOMOR 1 / TAHUN 2016}

\section{Uji Hipotesis}

Uji regresi linear sederhana digunakan untuk mengetahui pengaruh variabel independen secara parsial terhadap variabel dependen. Uji regresi linear sederhana ini digunakan untuk menguji hipotesis pertama (Keadilan Prosedural berpengaruh positif terhadap Kinerja karyawan), hipotesis kedua (Keadilan Prosedural berpengaruh positif terhadap kepuasan karyawan).

Analisis jalur (Path Analysis) merupakan pengembangan dari analisis regresi, sehingga analisis regresi dapat dikatakan sebagi bentuk khusus dari analisis jalur. Analisis jalur digunakan untuk melukiskan dan menguji model hubungan antar variabel yang berbentuk sebab akibat (bukan bentuk hubungan sebab akibat). Melalui analisis jalur ini akan dapat ditemukan jalur mana yang paling tepat dan singkat suatu variabel independen menuju variabel dependen yang terakhir (Sugiyono, 2007: 297) yang dapat dilakukan oleh analisis jalur (path analysis) adalah menentukan pola hubungan antara tiga atau lebih variabel dan tidak dapat digunakan untuk mengkonfirmasi atau menolak hipotesis kausalitas imajiner (Imam Ghozali, 2011: 250). Setelah menentukan jalur mana yang paling tepat kemudian jalur tersebut akan diuji menggunakan penrhitungan sobel test. Perhitungan sobel test digunakan untuk menguji hipotesis ketiga, yaitu Keadilan
Prosedural berpengaruh positif terhadap Kinerja Karyawan melalui Kepuasan Karyawan.

\section{HASIL PENELITIAN DAN PEMBA- HASAN}

\section{Kecenderungan Variabel}

Kecenderungan variable Keadilan Prosedural, Kepuasan Karyawan, dan Kinerja Karyawan disajikan sebagai berikut: Tabel 1. Frekuensi Keadilan Prosedural

\begin{tabular}{ccccc}
\hline No. & $\begin{array}{c}\text { Interva } \\
\text { l }\end{array}$ & Frek & $\%$ & Ktg. \\
& \multicolumn{1}{c}{. } & & \\
\hline 1. & $<36$ & 1 & $1,72 \%$ & Buruk \\
\hline 2. & $36-54$ & 29 & $50,00 \%$ & Cukup \\
\hline 3. & $>54$ & 28 & $48,28 \%$ & Baik \\
\hline
\end{tabular}

Tabel 1 menunjukkan bahwa data responden terbanyak memiliki kategori baik sebesar 48,28\% sedangkan pada kategori cukup sebanyak 50,00\% responden. Pada kategori buruk, hanya terdapat $1,72 \%$ responden. Oleh karena itu dapat disimpulkan bahwa Keadilan Prosedural di Universitas Negeri Yogyakarta berada pada kategori cukup.

Tabel 2. Frekuensi Kepuasan Karyawan

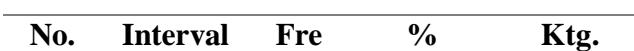

k.

\begin{tabular}{ccccc}
\hline 1. & $<74$ & 2 & $3,45 \%$ & Rendah \\
\hline 2. & $74-111$ & 48 & $82,76 \%$ & Sedang \\
\hline 3. & $>111$ & 8 & $13,79 \%$ & Tinggi
\end{tabular}

Tabel 2 menunjukkan bahwa data responden yang terbanyak terdapat pada kategori sedang yaitu sebanyak 82,76\%, 


\section{JURNAL NOMINAL / VOLUME V NOMOR 1 / TAHUN 2016}

selanjutnya diikuti oleh kategori tinggi terdapat $13,79 \%$. Terdapat $3,45 \%$ yang berkategori rendah pada variabel ini. Jadi, dapat ditarik kesimpulan bahwa Kepuasan Karyawan di Universitas Negeri Yogyakarta berkategori sedang.

Tabel 3. Frekuensi Kinerja Karyawan

\begin{tabular}{ccccc}
\hline No. & Interval & Frek & $\%$ & Ktg. \\
& & $\cdot$ & & \\
\hline 1. & $<20$ & 0 & $0,00 \%$ & Buruk \\
\hline 2. & $20-30$ & 27 & $46,55 \%$ & Cukup \\
\hline 3. & $>30$ & 31 & $53,45 \%$ & Baik \\
\hline
\end{tabular}

Tabel 3 menunjukkan bahwa responden terbanyak terdapat pada kategori baik, yakni sebanyak 53,45\%. Kemudian sisanya pada kategori sedang sebanyak 46,55\% karena tidak terdapat responden pada kategori buruk. Dengan demikian dari data tersebut memiliki kesimpulan bahwa Kinerja Karyawan di Universitas Negeri Yogyakarta berada pada kategori baik.

\section{Uji Hipotesis}

Regresi linear sederhana digunakan untuk mengetahui pengaruh variabel independen secara parsial terhadap variabel dependen. Regresi linear sederhana digunakan untuk menjawab $\mathrm{H} 1$ dan $\mathrm{H} 2$. Nilai masing-masing regresi disajikan pada tabel 1 dan 2.

Tabel 1. Rangkuman Hasil Analisis Hipotesis 1

\begin{tabular}{llll}
\hline Variabel & Koef. & thitung & Sig. \\
& Reg.
\end{tabular} .

\begin{tabular}{lccc}
\hline Konstanta & 15,119 & & \\
Keadilan & 0,300 & 5,995 & 0,000 \\
Prosedural & & & \\
$R$ Square $=0,391$ & & & \\
\hline
\end{tabular}

Sumber: Data Primer yang Diolah

Berdasarkan hasil perhitungan linear sederhana yang ditunjukkan pada Tabel 1 di atas, maka persamaan regresi sebagai berikut:

$$
\mathrm{Y}=15,119+0,300 \mathrm{X} 1
$$

Persamaan tersebut menunjukkan bahwa nilai koefisien regresi Keadilan Prosedural (X1) sebesar 0,300 dan nilai konstanta sebesar 15,119 yang berarti jika variabel independen dianggap konstan (independen $=0$ ), maka nilai Kinerja Karyawan (Y) adalah 15,119.

Hasil perhitungan regresi linear sederhana menunjukkan nilai $\mathrm{t}$ hitung sebesar 5,995. Jika dibandingkan dengan t tabel pada tingkat signifikansi 0,05 dengan df $=58-2=56$ sebesar 1,672, maka $\mathrm{t}$ hitung lebih besar dari $\mathrm{t}$ tabel $5,995>1,672)$. Oleh karena itu, hipotesis pertama (H1) yang menyatakan bahwa Keadilan Prosedural berpengaruh positif terhadap Kinerja Karyawan di UNY diterima.

Hasil penelitian ini didukung oleh penelitian yang dilakukan oleh Siti Hidayah dan Haryani (2013) yang menyatakan bahwa Keadilan Prosedural berpengaruh positif dan signifikan terhadap Kinerja Karyawan pada Karyawan BMT Hudatama Semarang. 


\section{JURNAL NOMINAL / VOLUME V NOMOR 1 / TAHUN 2016}

Tabel 2. Rangkuman Hasil Analisis Hipotesis 2

\begin{tabular}{lccc}
\hline Variabel & $\begin{array}{c}\text { Koef. } \\
\text { Reg. }\end{array}$ & thitung & Sig. \\
\hline $\begin{array}{l}\text { Konstanta } \\
\text { Kepuasan }\end{array}$ & 37,838 & & \\
Karyawan & 1,118 & 4,995 & 0,000 \\
$R$ Square $=0,308$ & & & \\
\hline
\end{tabular}

Sumber: Data Primer yang Diolah

Berdasarkan hasil perhitungan linear sederhana yang ditunjukkan pada Tabel 2 di atas, maka persamaan regresi sebagai berikut:

$$
\mathrm{Y}=38,838+1,118 \mathrm{X} 2
$$

Persamaan tersebut menunjukkan bahwa nilai koefisien regresi Keadilan Prosedural (X2) sebesar 1,118 dan nilai konstanta sebesar 38,838 yang berarti jika variabel independen dianggap konstan (independen $=0$ ), maka nilai Kepuasan Karyawan (Y) adalah 38,838.

Hasil perhitungan regresi linear sederhana menunjukkan nilai $\mathrm{t}$ hitung sebesar 4,995. Jika dibandingkan dengan $\mathrm{t}$ tabel pada tingkat signifikansi 0,05 dengan $\mathrm{df}=58-2=56$ sebesar 1,672, maka $\mathrm{t}$ hitung lebih besar dari $\mathrm{t}$ tabel $4,995>1,672$. Oleh karena itu, hipotesis kedua (H2) yang menyatakan bahwa Keadilan Prosedural berpengaruh positif terhadap Keinerja Karyawan di UNY diterima.

Hasil penelitian ini didukung oleh penelitian yang dilakukan oleh
Rakhmawati Hajiyanti Muji Rahayu (2013) yang menyatakan Keadilan Prosedural berpengaruh positif terhadap Kepuasan Karyawan pada PT Pelabuhan Indonesia III (Persero) Cabang Tanjung Emas Semarang.

Path analysis digunakan untuk melukiskan dan menguji hubungan antar variabel yang berbentuk sebab akibat sehingga dapat ditemukan jalur mana yang paling tepat dan singkat suatu variabel independen menuju variabel dependen yang terakhir (Sugiyono, 2007: 297).

Tabel 3. Rangkuman Hasil Analisis Hipotesis 3

\begin{tabular}{lccc}
\hline Variabel & $\begin{array}{c}\text { Koef. } \\
\text { Reg. }\end{array}$ & t $_{\text {hitung }}$ & Sig. \\
\hline $\begin{array}{l}\text { Konstanta } \\
\text { Keadilan }\end{array}$ & 12,161 & & \\
$\begin{array}{l}\text { Prosedural } \\
\text { Kepuasan }\end{array}$ & 0,215 & 3,765 & 0,000 \\
Karyawan & 0,076 & 2,684 & 0,000 \\
$R$ Square $=0,461$ & & & \\
\hline
\end{tabular}

Sumber: Data Primer yang Diolah

Berdasarkan hasil perhitungan linear sederhana yang ditunjukkan pada Tabel 3, dapat dilakukan perhitungan path analysis sebagai berikut: 


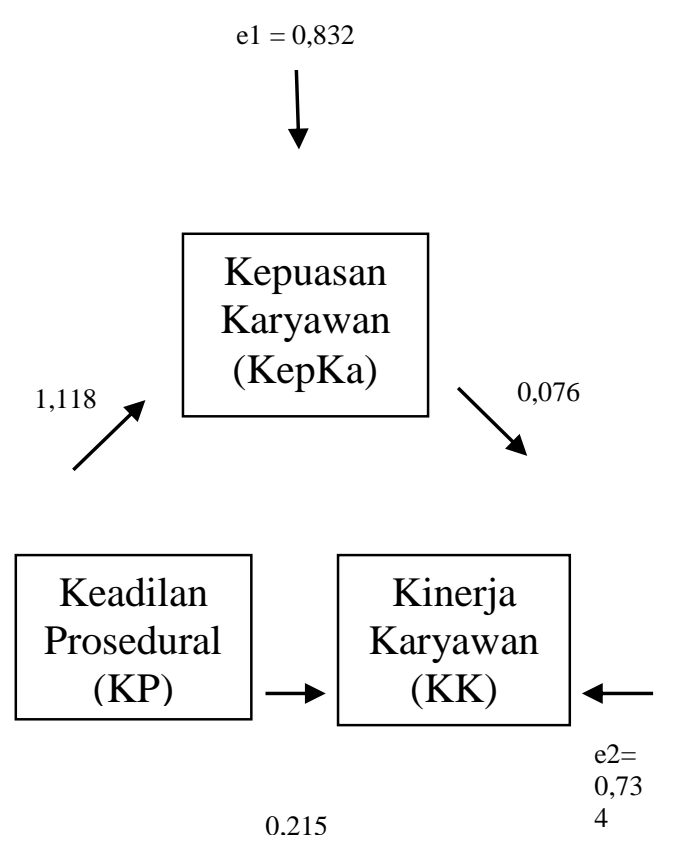

Gambar 1. Path Analysis

Berdasarkan gambar 1 dapat dilakukan perhitungan sobel test seehingga memeperoleh t hitung, yaitu:

$$
\mathrm{t}=\frac{0,0849}{0,0361}=2,348
$$

Berdasarkan hasil perhitungan maka diperoleh nilai t hitung 2,348 lebih besar dari t tabel (tingkat signifikansi 0,05 dengan $\mathrm{df}=58-2=56$ ) sebesar 1,672 dan memiliki koefisien mediasi 0,085 yang diperoleh dari hasil regresi linear Keadilan Prosedural $(1,118)$ dikalikan dengan hasil regresi linear Kepuasan karyawan (0,076). Oleh karena itu, hipotesis ketiga (H3) yang menyatakan bahwa Keadilan Prosedural berpengaruh positif terhadap Kinerja Karyawan melalui Kepuasan Karyawan diterima.
Hasil penelitian ini didukung oleh penelitian yang dilakukan oleh Aryo Primanda Misbahuddin Azzuhri (2013) disebutkan bahwa terdapat pengaruh langsung antara Kepuasan Kerja terhadap Kinerja Karyawan secara positif dan juga Motivasi Kerja secara tidak langsung berpengaruh positif terhadap Kinerja Karyawan melalui Kepuasan Kerja pada Kantor Pusat PT Varia Usaha Gresik.

\section{SIMPULAN DAN SARAN}

\section{Simpulan}

Berdasarkan hasil analisis dan pembahasan mengenai pengaruh Keadilan Prosedural terhadap Kinerja Karyawan dengan Tingkat Kepuasan Karyawan sebagai Variabel Intervening di UNY, maka dapat ditarik kesimpulan sebagai berikut:

1. Keadilan Prosedural berpengaruh positif terhadap Kinerja Karyawan. Hal ini ditunjukkan pada hasil regresi linear sederhana yang memiliki nilai t hitung sebesar 5,995 yang lebih besar dari $\mathrm{t}$ tabel sebesar 1,672. Pengujian ini diperoleh persamaan $\mathrm{Y}=15,119+0,300$ $\mathrm{X} 1$ yang memiliki arti bahwa koefisien bernilai positif. Dapat disimpulkan bahwa Keadilan Prosedural berpengaruh positif terhadap Kinerja Karyawan, maka $\mathrm{H}_{1}$ diterima. 


\section{JURNAL NOMINAL / VOLUME V NOMOR 1 / TAHUN 2016}

2. Keadilan Prosedural mempunyai pengaruh positif terhadap Kepuasan Karyawan. Hal ini ditunjukkan pada hasil regresi linear sederhana yang memiliki nilai t hitung sebesar 4,995 yang lebih besar dari t tabel sebesar 1,672. Pengujian ini diperoleh persamaan $\mathrm{Y}=38,838+1,118 \mathrm{X} 2$ yang memiliki arti bahwa koefisien bernilai positif. Dapat disimpulkan bahwa Keadilan Prosedural berpengaruh positif terhadap Kepuasan Karyawan, maka H2 diterima.

3. Keadilan Prosedural berpengaruh positif terhadap Kinerja Karyawan yang dimediasi oleh Kepuasan Karyawan. Nilai t hitung lebih besar dari $\mathrm{t}$ tabel, besar $\mathrm{t}$ hitung adalah 2,348 dan t tabel 1,672 dan koefisien mediasai 0,085 sehingga dapat ditarik kesimpulan bahwa Keadilan Prosedural berpengaruh positif terhadap Kinerja Karyawan yang dimediasi oleh Kepuasan Karyawan, maka H3 diterima.

\section{Saran}

Berdasarkan hasil penelitian dan kesimpulan di atas, maka dapat disarankan:

1. Bagi Universitas Negeri Yogyakarta a. Instansi (atasan) diharapkan dapat mengambil keputusan dengan melibatkan pihak yang memiliki kompetensi dan wewenang di bidangnya sehingga dapat meminimalkan tingkat kesalahan yang akan terjadi.

b. Pengambil keputusan (atasan) diharapkan dapat bertanggung jawab atas keputusan yang diambilnya dengan kata lain berani mengakui kesalahan akan keputusan yang diambil.

c. Instansi (atasan) diharapkan dapat lebih mendekatkan diri terhadap para pegawai sehingga pegawai dapat terbuka kepada atasan akan permasalahan yang terjadi di dalam instansi dan atasan dapat membantu menyelesaikan permasalahan ataupun menghindarikan keadaan dimana hal tersebut dapat memicu timbulnya rasa ketidaknyamanan para pegawai, dan akan berdampak negatif pada kinerja mereka.

2. Bagi Peneliti Lain

a. Penelitian selanjutnya diharapkan dapat menggunakan objek lebih dari satu ataupun membandingkan antara satu perusahaan dengan perusahaan lain seperti perusahaan swasta dan instansi negeri, sehingga data penelitian lebih variatif dan 


\section{JURNAL NOMINAL / VOLUME V NOMOR 1 / TAHUN 2016}

kemampuan generalisasi lebih baik.

b. Penelitian selanjutnya diharapkan dapat lebih memperhatikan kualitas dari responden seperti pemilihan responden yang memang benar-benar mau ataupun berkenan untuk berkontribusi dalam pengisian kuesioner agar data yang diperoleh peneliti sesuai seperti yang diharapkan dan memudahkan peneliti dalam penggunaannya untuk kepentingan penelitian.

\section{DAFTAR PUSTAKA}

Elis Sholihah. (2014). "Pengaruh Budaya Organisasi Terhadap Kinerja Karyawan Di Kota Bunga Puncak Kabupaten Cianjur". Skripsi. Sekolah Tinggi Ilmu Ekonomi ISM Jakarta.

Hani Handoko. (2003). Manajemen. Yogyakarta: BPFE.

Imam Ghozali. (2011). Aplikasi Analisis ultivariate dengan Program IBM SPSS 19. Semarang: Badan Penerbit Universitas Diponegoro.

Muhammad Arif Listyantara. (2009). "Pengaruh Keadilan Distributif, Keadilan Prosedural, dan Keadilan Interksional Terhadap Kepuasan Kerja" (Studi Kasus Pada PT. Solo Sentral Taksi)". Skripsi. Universitas Muhammadiyah Surakarta.

Rakhmawati Hajiyanti Muji Rahayu. (2013). "Pengaruh Keadilan Prosedural Terhadap Komitmen Karyawan Dengan Tingkat Kepuasan Karyawan
Sebagai Variabel Intervening”. Skripsi. Universitas Negeri Yogyakarta.

Siti Hidayah dan Haryani. (2013). "Pengaruh Keadilan Distributif dan Keadilan Prosedural Terhadap Kinerja Karyawan BMT Hudatama Semarang". Jurnal EkonomiManajemen-Akuntansi No.35.

Sugiyono. (2007). Statistika untuk Penelitian. Bandung: Alfabeta. . (2014). Metode Penelitian Kunatitatif, Kualitatif, dan $R \& D$. Bandung: Alfabeta.

Yesi Mutia Basri. (2009). "Hubungan Antara Keadilan Prosedural, Job Stress, Komitmen Organisasi dan Keinginan Berpindah Akuntan (Study pada Tenaga Akuntansi di Provinsi Riau dan Kabupaten Bengkalis)". Jurnal. 